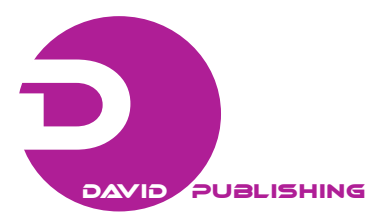

\title{
Implementing BIM in the German Architecture, Engineering and Construction Market-A Survey about the Potentials and Barriers
}

\author{
Petra von Both \\ Building Lifecycle Management Department, Karlsruhe Institute of Technology, Karlsruhe 76131, Germany
}

\begin{abstract}
The research project "BIM-Potentials and Barriers" aims to analyze existing BIM practice and the barriers to the implementation of the approach in Germany. Overseen by an "advisory board" with high-profile field, public-authority and AEC (architecture, engineering and construction market) association representatives, a set of hypotheses has been drawn up and subjected to evaluation by means of a detailed survey. The survey, having identified the relevant stakeholders, first attempts to discover how BIM (building information modeling) is currently used. The potentials of the application of BIM in the different processes and target groups are also determined, as well as the barriers and constraints. Enhancement of the considered areas is an important project solution approach: Besides technological aspects, the analysis also focuses on contracting, norms and processes, as well as education, knowledge and role perception.
\end{abstract}

Key words: BIM, survey, collaborative engineering, virtual engineering, product modelling.

\section{Introduction}

Despite the efforts made to enhance its efficiency, the construction sector has been unable to improve its productivity effectively. An American study published by the National Institute of Building Science (Fig. 1) that compares the productivity of the construction sector with other industrial sectors even suggests that the trend has been downwards over the past 40 years. This indicates that innovative means and methods need to be applied [1].

Implementation of the BIM method in Germany is still at its very early stages. In comparison with the US and the Nordic countries, the German AEC (architecture, engineering and construction market) sector has yet to exhaust the potentials of the method and technology. Although software vendors already offer BIM (building information modeling) solutions adapted to German processes (such as the German

Corresponding author: Petra von Both, Dr., Prof., research fields: civil engineering informatics, virtual engineering and systems engineering. E-mail: petra.vonboth@kit.edu. statutory size specifications), with the exception of a few general contractors and public-authority pilot projects, few practitioners use these applications to calculate project-related resources, costs, revenue and overall profitability.

It would seem that the fine, granular organizational structure of the German AEC market is one of the barriers to the integrated adoption of the BIM method. Besides strong functional segmentation of the processes into separate companies, the size of the companies involved too is critical for generating global added-value: Over $92 \%$ of construction companies employ less than 20 individuals [2] and the average size of an architects' or engineers' office is between three and five employees [3].

In this context, special attention needs to be paid to the poor economic situation of architects and other planners in Germany: Only around 50\% of architects and engineers calculate project-related resources, costs, revenue and overall profitability, and the annual profit of around $30 \%$ of design offices is $€ 15,000$ or less [3]. With respect to working methods, most adhere to 


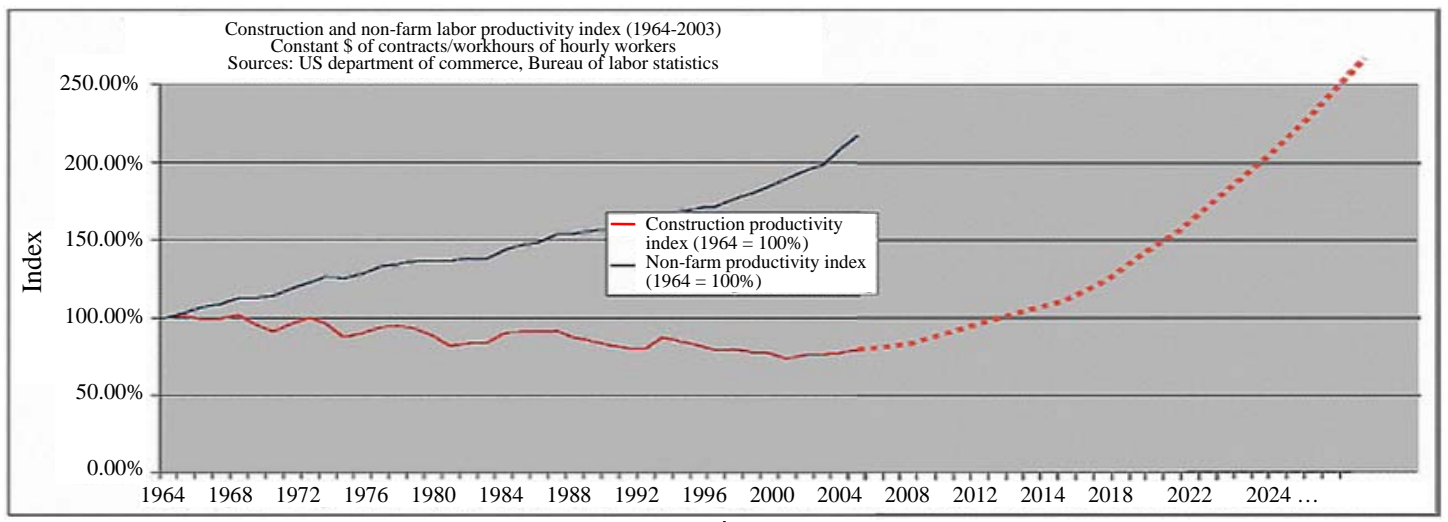

Fig. 1 Labor productivity index for the US construction industry and all non-farm industries from 1964 to 2003, NIBS (National Institute of Building Science) 2007.

antiquated principles, and the benefits of the software are not exhausted in the slightest, with even modern model-based CAD (computer-aided design) systems used purely as "digital 2D drawing boards". Thus, possible added-value through high-density and high-quality information in the planning and subsequent lifecycle phases is not exploited.

The elaboration of a specific action plan to ameliorate this situation seems difficult because reliable analyses concerning the application of BIM in Germany have yet to be carried out.

\section{Building Information Modelling}

The strategic goal of BIM is the development and utilization of an integrated building data model for the digital representation of building-descriptive information throughout the whole lifecycle of a building. Following an integrated and systemic approach, all relevant object-related domain aspects are to be represented and provided to the participants of the collaborative process.

This data model should also serve as an informational base for coupling AEC software applications involved in the building modeling process. Floor plans, elevations, detail plans, bills of quantities and other lists represent specific model view sand can be generated by the BIM software from the current model.

In summary, a BIM can be described as a digital model that represents, links and manages all the geometrical and semantic aspects of a building (e.g., energetic properties, used materials, costs, etc.). The model describes the components and spaces of a building, their structure and topology as well as their properties. Thus, it allows for the realization of integrated, computer-aided planning, construction and object management [4].

As intelligent parametric objects, the model elements can also contain rule-based knowledge about their modeling behavior (methods), such as the scaling behavior of stairs.

The benefits of the BIM-based approach are evident:

- continuous provision of consistent models for all project partners and software applications;

- avoidance of loss of information;

- basis for model validation and simulation with respect to constructive, functional, ecological, economical and aesthetic aspects (e.g., lifecycle costing or design review);

- enhancement of decision-making processes through a more reliable information base;

- higher planning and substantive quality through earlier detection, communication and coordination of constructive problems, e.g., by using software for clash detection;

- improved discussion and validation of design alternatives through model-based 3D-VR (visualization) and easy fabrication of physical models 
(rapid prototyping);

- reduction of addendums through reliable quantity models;

- automated fabrication (CAD-CAM (computeraided manufacturing) coupling);

- consistent building documentation for object and facility management.

\section{Methodical Approach}

The research project "BIM-Potentials and Barriers" initiated in May 2010 aims to analyze existing BIM practice and the barriers preventing penetration of the approach.

Overseen by an "advisory board" with high-profile field, public-authority, AEC association and building SMART initiative representatives, a set of hypotheses has been drawn up and subjected to evaluation by means of an online survey.

Enhancement of the considered areas is an important project solution approach. Besides technological aspects, the analysis also focuses on contracting, norms and processes.

With respect to the generation of added-value, the current discussion does not differentiate between the project and company context-but one of the reasons for BIM's lack of success seems to be the disparity between projects that generate value early on and projects that generate value in later lifecycle phases. Thus, especially during the initial project phases, when the architect generally models the first building representation and builds the structural base for the whole BIM lifecycle, there is a gap between the created value for the project and the direct company-internal benefit for the architect's office- - with more effort than normal invested.

Also considered were model quality and integration into contract management. There are still no reliable specifications as regards quality criteria for BIM models that could serve as mandatory guidelines.

Based on the hypotheses outlined above, a four-part questionnaire was drawn up. First participants are classified to determine their functions, their roles in the project, the size of their companies, the project volumes, etc.. Different target groups are addressed with different questions, including planners and designers, construction firms, investors/building owners, facilities managers and public authorities.

The survey then tries to determine how BIM is currently used in the German AEC market, i.e., the different levels of application-from 2D drawing to pure geometric 3D and object-oriented modeling. Integration of process data (4D) and cost and quantity information (5D) then takes places. By asking for specific information regarding processes and activities, a detailed overview can be obtained.

The potentials of the application of BIM in the different processes and target groups are analyzed, including the expectations of those inexperienced and experienced in its use. Here the survey attempts to determine estimations of the possible (future) benefit and the willingness to implement BIM within companies.

Besides the potentials, the survey also tries to highlight the barriers and constraints of the BIM approach—on a technological and organizational level.

\section{Results}

The following section describes several of the most noticeable results as follows.

\subsection{Participants and Target Groups}

The survey was addressed at planners, construction companies, investors and project developers, facility managers and the public sector. These target groups were contacted with the help of the respective German confederations and associations. Information about the survey was also communicated via the information channels of the AEC software vendors. All this ensured that the response rate was high.

The majority of the participants were planners (architects and engineers: 57\%), followed by building owners (21\%) and construction companies (11\%). 


\subsection{Status Quo}

The survey showed that the percentage already using the BIM method is quite high. However, BIM is only one method among others and is applied as an exclusive strategy only in exceptional cases. So on average, two to three different methods are applied simultaneously in projects or companies. To date, 2D planning is the most popular method used.

Planners in particular are using the software for pure $2 \mathrm{D}$ planning (60\% of overall usage), as are construction companies (70\%).

Also of interest is the extent to which BIM is used in the different AEC processes, this is shown in Fig. 2.

BIM is the favorite method, especially in the early design phases. It is used for over $77 \%$ of visualizations and $66 \%$ of design planning work. When it comes to detailing (52\%), sampling (33\%), preparation for tender (37\%), and construction-work scheduling its popularity decreases. Astonishingly, use of the model-based method in the area of facilities management is low (22.4\%).
A similar picture can be drawn in relation to data exchange: The dominant exchange formats, regardless of the target group, are still paper, PDF and Auto Desks CAD-format DWG. Use of model-based formats - including by BIM users-remains very rare. This can be seen as an indicator of the lack of model-based working cooperation partners and also insufficient technical interfaces.

With respect to project size, use of BIM rises, especially in projects over $€ 2$ million. A similar correlation exists concerning the size of the enterprise: In companies with up to 10 employees, the number of non-BIM-users is higher than average. The highest number of BIM users is found in medium-sized enterprises with between 3 and 300 employees. Companies with over 300 employees generally are not using BIM at the moment but are willing to do so in the near future.

Participants also answered questions regarding how they viewed the switch to BIM. It is noticeable that in most cases the switch had been for a specific project and not implemented throughout the whole company. This

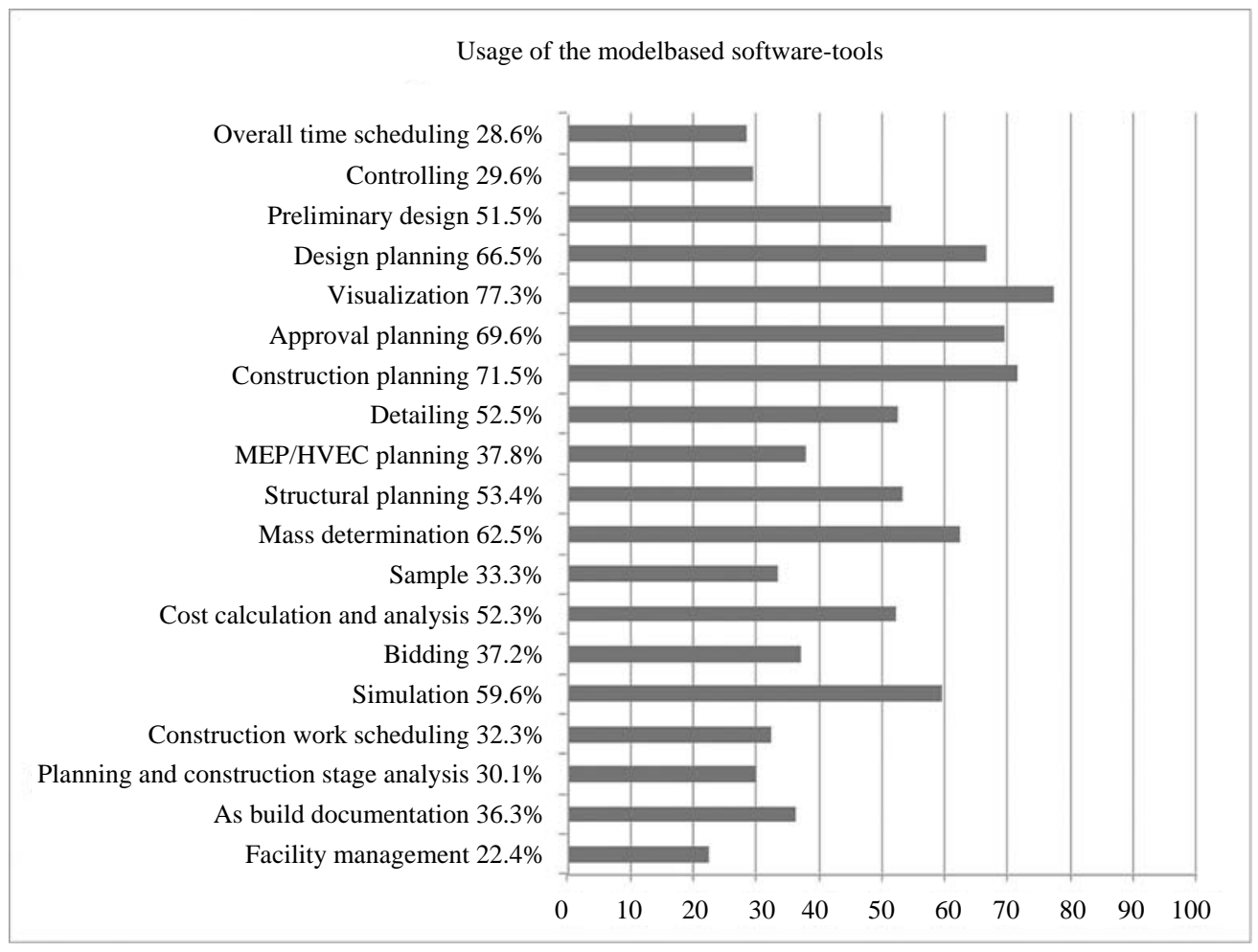

Fig. 2 Use of model-based software tools. 
shows that on the one hand the motivation for change often comes from project partners, and on the other that a project-based change minimizes the risk as well as the required number of specially-trained individuals.

The thematic widening of the survey to include commercial topics revealed very interesting correlations: BIM is currently used in particular by stakeholders who attach great importance to efficient corporate management. The biggest correlation was in relation to quality management, project management and process orientation. Thus, 34\% of BIM-users are DIN-ISO 9001-certified but only 9\% of non-BIM users have the same certification.

BIM users also make the greatest use of project manuals/project protocols with defined standards, processes and responsibilities, at $47 \%$. The use of web-based collaboration platforms by BIM users is also twice as high (42\%) as by non-BIM users.

When it comes to process orientation, construction firms are highly process-oriented. The feedback from the public sector and the planners, especially architects, points to only marginal process orientation for these groups. The specification of decision processes, tasks and responsibilities also seems to be a unique characteristic of BIM users.

\subsection{Experiences and Benefits of the BIM Method}

In summary, all the target groups claimed to have benefited from the BIM method (Fig. 3). Of note here are three groups: investors/building owners who benefited the most in relation to all aspects, and the public sectors and building-services engineers who benefited the least.

Detailed query provided feedback on the different aspects: all target groups reported only marginal benefits in relation to resource management for the project and the coordination efforts among project partners.

In the public sector, coordination efforts remained unchanged, while support of internal sequent processes on average declined. Building service engineers stated that project change-management effort had increased, although multiple-entry effort had decreased.

Project resource allocation and time expenditure remained almost unchanged with a slightly negative tendency. However, despite the neutral to slightly negative assessment of these areas, the company's internal added-value and project-oriented added-value on average were enhanced.

Within the other target groups (project managers, controllers, architects, structural engineers and general

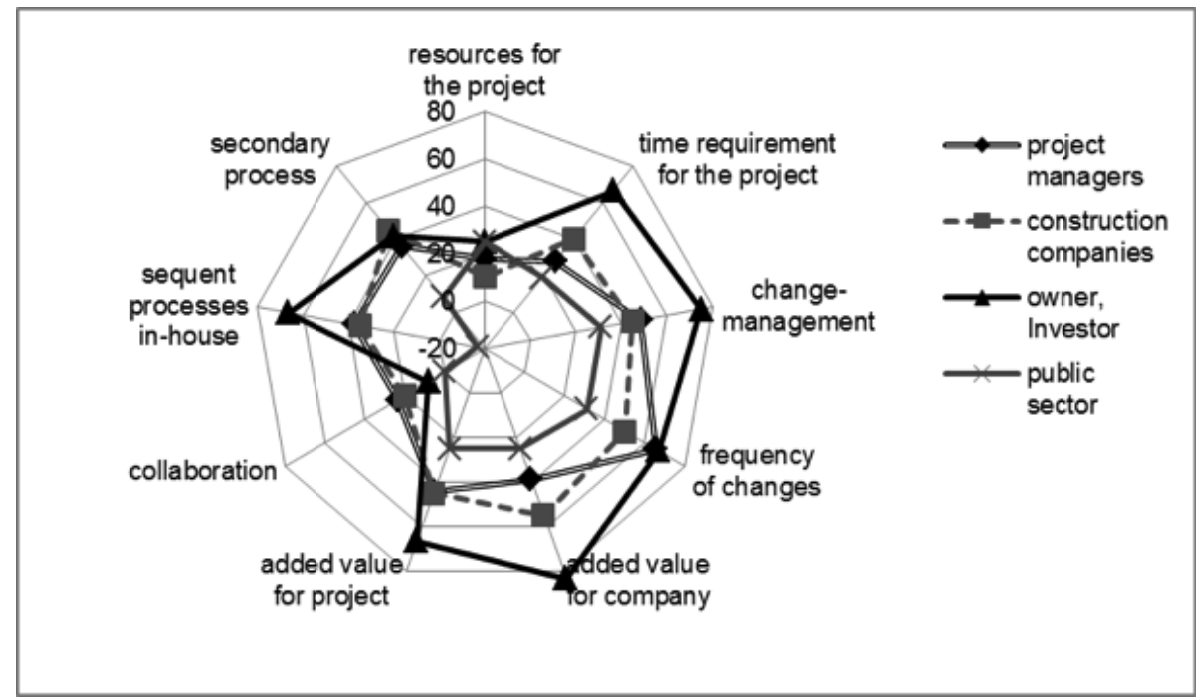

Fig. 3 Assessment of the benefits of the BIM method for experienced user groups. 

Market-A Survey about the Potentials and Barriers

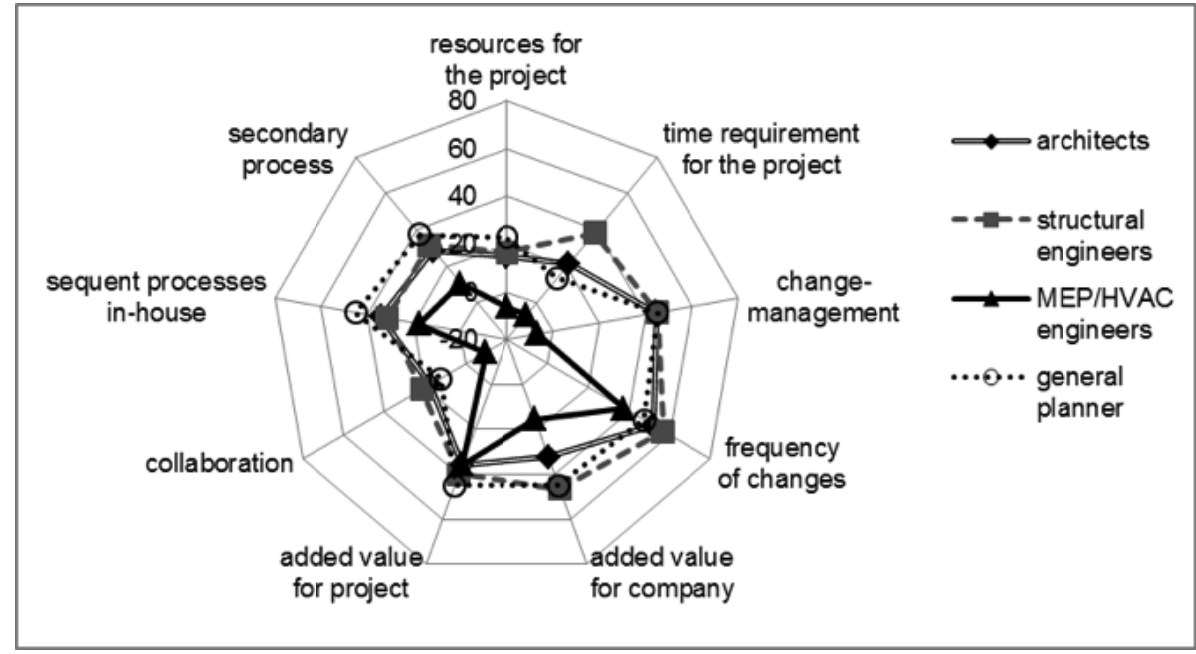

Fig. 4 Assessment of the benefits of the BIM method for experienced users (planners).

contractors reported fewer benefits with respect to project time expenditure.

\subsection{Technological Barriers to the Implementation of BIM}

Evaluation of the hypotheses concerning technological aspects reveals remarkable differences: BIM-users and non-BIM-user differ when it comes to the questions regarding hardware requirements and the complexity of model-based software.

Whereas BIM-users described the hardware requirements as unproblematic, they seem to be a barrier for non-BIM users. Similar differences are encountered in the statements concerning the complexity of BIM software: Non-BIM users agreed that "the complexity of BIM software is too high", whereas experienced BIM users did not consider this a problem.

Interestingly there is similarity in the degree of agreement when it comes to the statement that model-based BIM software has functional limitations. Interoperability in particular seems to be a major problem. While BIM users assessed the effort required to import data into the model-based software as fairly problematic, for non-BIM-users it seems to be a considerable barrier (Fig. 5).

Asked about data exchange standards, all groups

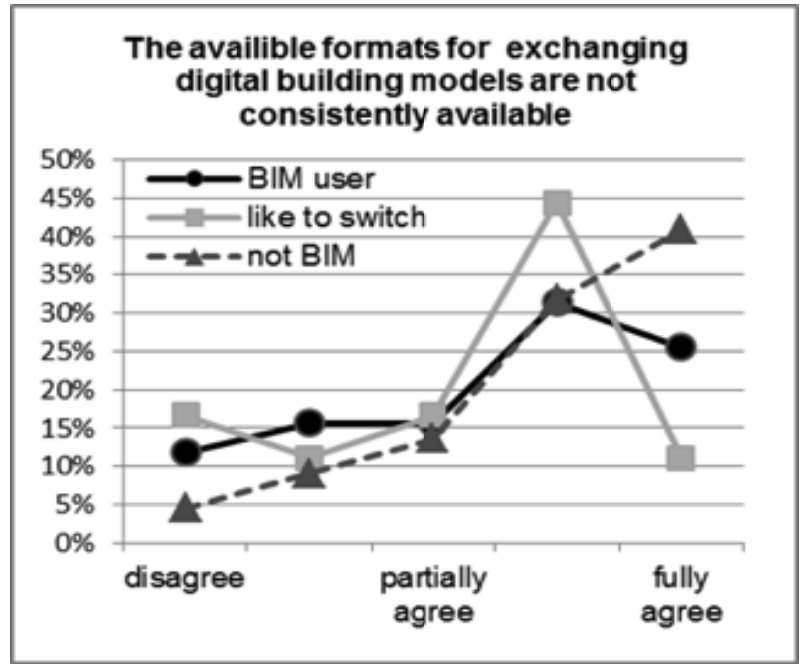

Fig. 5 Agreement/disagreement with the statement "The available formats for exchanging digital building models are not consistently available”.

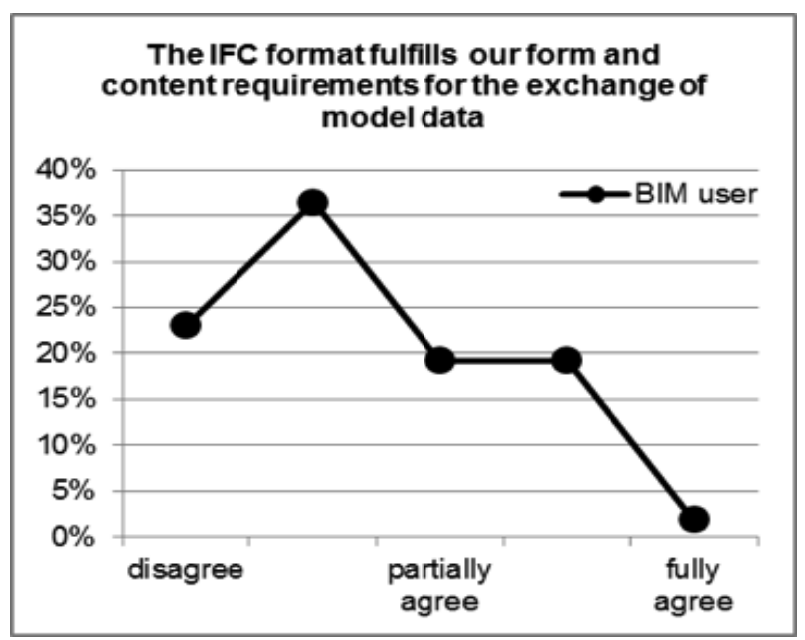

Fig. 6 Assessment of the adequacy of the IFC format. 
agreed with the statement that the existing exchange formats for digital building models are not consistently available. The IFC (industry foundation classes) format in particular and its implementation in software interfaces still do not fulfill the requirements of the target groups (Fig. 6).

\subsection{Economic Barriers}

One high barrier for non-BIM users seems to be the availability of capital for investment. For those already using BIM software the financial aspect does not seem to be a barrier or problem. Non-BIM users agreed that they did not have enough financial resources for BIM-related investments.

Also, the phase-oriented awarding of contracts was seen to be a general barrier. Those involved are unable to enhance their added-value as would be possible with overarching integrated work, nor is the model-based method applied continuously.

\subsection{Normative Barriers}

Standardization is an important auxiliary means for simplified and secure contracting. By referring to normative descriptions, contracts can be concluded efficiently and securely between clients and planners/contractors as well as between planners themselves. This becomes very important when contract partners-as in Germany-are newly composed for each project.

When applying the BIM method, project partners exchange models rather than blueprints or drawings. This allows for an integrated process without media interruption. Especially in the case of model changes it is beneficial to extract data directly out of the model. This demands a consistent model but also clearly specified exchange parameters and quality criteria. But how does this work in practice? The participants of the survey agreed strongly (65\%) with the statement that the form and content quality of digital building models is as yet insufficiently standardized (Fig. 7).

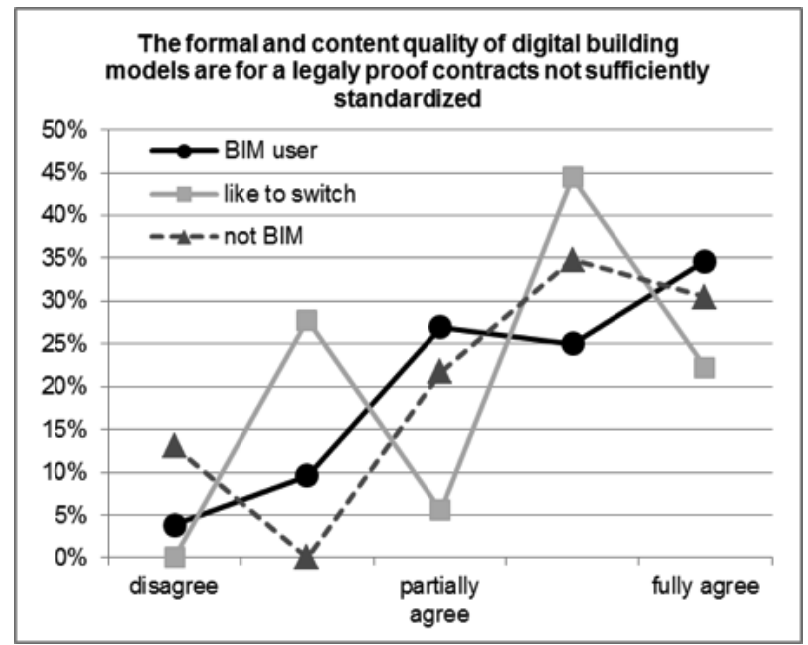

Fig. 7 Agreement/disagreement with the statement that the form and content quality of digital building models is as yet insufficiently standardized.

\subsection{Educational Barriers}

The skills and abilities of entrants into BIM-relevant areas - with the exception of those in possession of the CAD qualification-are rated collectively as below average and insufficient.

The constant negative assessments-by non-BIM users as well as BIM users - of methodical abilities, inter-disciplinary and trans-disciplinary thinking, process-orientation and comprehension of super-ordinated interdependencies and commercial aspects can be seen as indicating an urgent need for action.

A concluding and detailed statement on the educational situation in Germany is outside the scope of this project. The survey questions on educational barriers instead serve to complete the holistic examination of the general situation and to identify possible obstructive factors for the implementation of BIM.

\section{Conclusions}

The market analysis shows that, in addition to the still very vague understanding of the term "BIM", there is currently a high prevailing level of heterogeneity within the German construction industry when it comes 
to adaptation of the BIM method. This being the case, listing a number of blanket measures for all target groups therefore appears to make little sense. The study presented here is intended as a first step in the problem analysis process. The insights gained in this project-including in discussions with the group of experts and the associations and chambers involved in the survey-still permit some general conclusions. Identified deficits on a more conceptual level also allow the formulation of the existing need for research-related topics.

The high correlation with general measures for efficient corporate management and process-oriented action suggests that, in future debate, the methodology of BIM should be set in an overall context. BIM should be seen as a building block for efficient and cooperative/integrated project management and integrated into overall strategic corporate and collaboration planning.

With respect to the cooperative aspect, however, the survey made it clear that there are currently a large number of prejudices and reservations when it comes to sharing and collaborative use of BIM models between companies. What seems astonishing in this context in relation to research is the fact that, since the early 2000s, when the first approaches in the field of CSCW (computer supported collaborative work) [5] were introduced, hardly any new BIM-applicable approaches have emerged in the field of cooperation methodology. The developed approaches of internet-based information platforms (so-called project rooms) and groupware systems exist side-by-side and completely detached from newer model-based collaborative management approaches (see model server). The task of research must be to create concepts and prototype implementations for the integration of these approaches on the model and process levels.

The application of the integrated and collaborative working methods linked with the BIM methodology and the associated increased costs of coordination and synchronization enable new processes and responsibilities and roles to emerge that are insufficiently covered in "traditional project management”. Team-based approaches have yet to be practically formulated and are hardly feasible in the existing organizational and cooperative structures. The BIM introduction and usage processes have so far been implemented very individually by the different actors according to the respective corporate environment. The survey makes clear, however, the need that exists for generalized assistance and guidance. In order for a broader impact to be possible, more precise analysis of the pilot projects already implemented is required, and the question answered as to which experiences and individual findings can be generalized. This seems reasonable, especially in view of the on-going discussion regarding the definition of content and quality model standards (quality criteria).

Integrated planning needs to be more than just "technical" model management and the merging of different CAD models. One key question therefore is the localization of content-related quality assurance. Where should such content-related synchronization and quality assurance be anchored? Will the architect within such a context revert to being a substantive integrator, coordinator and thus process-relevant actor? What is obvious at any rate is that the clear need for additional integrating and coordinating activities is a key opportunity for the service sector. Determining which services can be commercialized and which roles they can be tied to in the extended process represents, in people's view, an interesting challenge for applied research, although the issues of utility, affordability and payment also need to be clarified.

On a practical level, the question of whether and how incentives and reward systems can be created to enable the shift of internal value-creation towards cross-process and cross-actor value creation for individual participants in a collaborative network also needs to be answered. New approaches to contracting appear necessary here. 
On the software and technology side, existing and potential future business models for integrated solutions also need to be examined. This relates in part to the much-needed improvements to the software interfaces (e.g., IFC) as well as to the developments in relation to the integration of model platforms and servers. The analysis of the commercial model-management systems that took place in the project and also the opinion of the interviewees of the so-called "model server" makes it clear that as yet there is seemingly no functional development and marketing business model that would motivate software vendors into developing such a solution. The extent to which open-source software prototypes developed within research projects such as the Open IFC Tools [6] can secure a broad appeal, or whether these, in comparison with commercial software, less quality-assured and "supported" tools will only be usable by specific target groups, remains to be seen. Closer examination of these market relationships, including of the latest financing models, such as crowd funding, seems therefore in people's view to be urgently required.

\section{References}

[1] P. Teichholz, Labor Productivity Declines in the Construction Industry: Causes and Remedies, AEC bytes Viewpoint, 2004, http://www.aecbytes.com/viewpoint /2004/issue_4.html (accessed Apr. 14, 2004).

[2] Statistical Yearbook 2010 for the Federal Republic of Germany, SFG Servicecenter Fachverlage, Federal Statistical Office, Reutlingen, 2010.

[3] C. Hommerich, T. Ebers, Analysis of the costs and revenues in architectural offices, in: The German Architectural Association, Bergisch Gladbach, 2006. (in German)

[4] P. Both, A collaborative approach for an integrated product lifecycle management, in: The CDVE (Cooperative Design, Visualization and Engineering) Conference, Palma de Mallorca, 2008.

[5] H. Grabowski, S. Rude, Information Logistics Computer-Aide Cross-Industry Cooperation, B.G. Teubner-Verlag, Stuttgart, Leipzig, 1999. (in German)

[6] Openifctools Home Page, www.openifctools.org (accessed Jan. 1, 2013). 